Editorial

\title{
What to do and not do in the development of a permanent program of pediatric cardiovascular surgery in an emerging country
}

\section{Dominican republic}

Motivation: a girl of 14 years of age, diagnosed at four of having a tetralogy of Fallot (TOF) that after several annual operatives by visitors teams, was never operated and when I met her in Christmas 2004 she wanted a gift from Santa: "To be operated and cure"

She died the following year without gift!

\section{Introduction}

In general almost all Latin American countries are underdeveloped having a high incidence of cardiovascular diseases and inappropriate care for the congenital (CHD) or acquired (AHD) heart diseases.

While the rest of the world was passing by their respective financial crisis in 2008-2009, some Latin American countries experienced sustainable growth: Brazil, Mexico, Chile and Colombia.

By principles of the year 2000 the Dominican Republic (DR) and Panama had shown sustained growth, but then DR was affected too with the global financial crisis of 2008-2009 and subsequent years.

\section{Shared problems with other countries of Latin America}

1. High birth rates (e.g. DR: 19.21 births/1000 population or 200,000 births per year. They behave like "human factories".

2. Statistics show that the global incidence of CHD is around $1 \%$ (1/100 births). On the Islands it seems more, due to inbreeding interaction / incest.

3. High maternal-child mortality ( $D R=20.4 / 1000$ births). After perinatal infections, congenital malformations are within the five leading causes of infant death where the CHD represent more than $40 \%$ of them

4. Anecdotal high incidence of AHD as rheumatic fever with valves sequels, infective endocarditis or viral myocarditis, etc.

5. Critical poverty / indigence: in DR $>60 \%$ of the population, (household income is less than $\$ 150$ per month).

6. Adolescent pregnancy is high with a shared high rate of premature births.

All this leads to a huge and prolonged waiting list for cardiac surgery.

\section{Ours strategies to address the problem}

In general, it is difficult to establish a strategy to offer the same service uniformly since each hospital or facility in the country is different in many aspects.
Volume 4 Issue I - 2016

Carlos J Troconis

Unidad Cardio Quirurgica Noreste, USA

Correspondence: Carlos J Troconis, M.D., Pediatrician, Pediatric Surgeon and Pediatric and Congenital Cardiac Surgeon, Unidad Cardio Quirurgica Noreste, USA, Tel 305-5882।8I,Email cjtroconis।@gmail.com

Received: December 22, 2015 | Published: January 06, 2016

We have to take into consideration cultural background, racial issues, historical resentments between the Dominican and Haitian, barriers of language, religious and political differences, etc.

\section{We were able to collect some data such as}

1. Annual regions demand for pediatric cardiac surgery services

2. Categorizations of incidences of these pathologies and their complexity (score for Risk Adjusted Congenital Heart Surgery -RACHS system), age, socio-economic stratification

3. Evaluation of existing infrastructures

4. Native local human resources and their academic preparation as well as of the institutions, continued medical education programs (CME)

5. Local providers of medicines and special cardiovascular products/ supplies

6. Government and various NGOs awareness about the problem

7. Concurrence of others cardiovascular NGO supporting programs

In early stages (2003), a revision of a long list from $1999-2002$ (3 years) for cardiovascular surgery at the Santiago Children's Hospital was done, numbers $=783$ cases, \pm 261 new cases per year. We perceived that the ventricular septal defects (VSD) were the most frequent cases within the waiting list for surgery; representing the $61 \%$ of the not cyanotic defects, followed by the tetralogy of Fallot as $31.1 \%$ of the cyanotic defects. Endorsing that in DR as most countries the commonest $( \pm 70 \%)$ pathologies are of simple complexity with the simplest surgical solution, meanwhile the intermediate ones and the more complex were \pm 20 and $10 \%$ respectively. Based on this review, at the beginning we focus our strategies in solve those simplest cases and a few of them of greater complexity not accepted by the various visiting teams were referred to the United States, the rest died waiting for surgery, less often I was able to carry my team from Venezuela to perform some high risk cases although the results were not so encouraging for the facts explained further down.

By 2005 the goals of the Save-A-Heart Foundation were not too different from previous NGO who visited the Dominican Republic for more than two decades, namely: 
1. Transfer of medical knowledge in cardiology and Pediatric Cardiac Surgery.

2. Bringing modern equipment ("donated") to the institutions chosen by the Foundation.

3. Our key difference was that our main objective was to create and develop two "permanent congenital and pediatric cardiac surgery programs" in conjoint ion with visiting teams of a "network of friends in the United States, Europe, Brazil, Colombia and Japan", hoping to be transformed with time into a Regional Centers of Excellence, one in Santiago and the other in Santo Domingo.

\section{Our philosophy has been based on: Lao Tsé (570 BC)}

"Give a man a fish and you feed him for a day, teach him to fish and you feed him for a lifetime" Comments on my first assessment trip on September of 2003 to Santo Domingo in a so-called institution CEDIMAT and Santiago at the Children's Hospital and its stakeholder foundation ("Hearts of the Cibao"):

Despite previous visits to the country by several NGO such as the Heart Care International, the International Kids Foundation, a group of Hospital Bambino Gesù from the Vatican, a team from Albany (USA), International Children Heart Foundation and others for Pediatric Cardiac Surgery, in annual or biannually engagements with "surgical operatives or missions", all with full support either from the visiting team and their specific NGO or several times from arrangement within institutions in partnership between the local government, the private sector (as independent entrepreneurs) with international and local Rotary clubs; there was not an established and permanent program of pediatric cardiac surgery for the reason that simply "none had left a legacy".

We observed for instance that major heart surgeries between visits were never performed, except some simplest ones as non-neonatal PDA occlusion and some ASD surgical closure. On interventional cardiology a few cases of atrial septostomy (Raskind type procedure) were done for cases with simple TGA and PFO, condemning them to a subsequent operation of Senning or Mustard instead of an Arterial Switch Operation as done nowadays in most advanced centers of the world.

It was often noted that when the visiting teams (so called "Americans") came to the hospital to perform their surgeries, all the operating rooms and makeshift areas of intensive care (ICU) were blocked for the "operatives", in effect were taken exclusively by the visiting team, misleading to a little interaction with local people. It is a widespread custom many other complaints as visitors being exclusivist; others felt ashamed by the language barrier and a few others been disgruntled because they had to interrupt their hospital daily duties, etc.

Countless and long waiting lists for unresolved surgical cases. We observed that "many families were disappointed without hope" with the visiting surgical team that were there and their children were not operated on, "it felt like having not won the Lottery" said often, "many of them were waiting a whole year for the great day that never came" creating false expectations with desperate frustration and sadness.

An interesting detail was that within the universe of hospitalized kids, those with congenital or acquired heart disease were the most expensive, due to their repeated hospitalizations with the aggravating circumstance of not been resolved after multiple opportunities, increasingly demanding greater attention and it affected the budget of the children's hospital. It became more expensive with further complexity. Meanwhile many succumbed with hypoxic spells or neurologic sequelae were established as a complication, others with advanced congestive heart failure (CHF) and quite a few developed pulmonary hypertensions $(\mathrm{PH})$. Those who survived became a heavy socio-economic load for the family and society, a tangible problem of national public health implications for the health system's authorities.

Indigence more than $75 \%$ of the patients were poor (family income $<150$ US\$ per month), large family groups (average 5 children) is the essence where often on "the youngest one is cared by the oldest teenage sister ( 12 years old) while mom is the livelihood as the figure of the father is absent". Consequently malnutrition, non-potable water and poor hygiene are common. On the socio economic evaluation of the patients and to assist them financially, we used as a parameters for the detection of critical poverty, that the vast majority have a "latrine" (primitive toilet) at home and also the lack of electricity was a shared issue.

Lack of specialized health programs nationwide heart diseases (congenital or acquired), other major surgeries or advanced treatments for childhood cancer are practically non-existent; if found they were insufficient and even ineffective. There is not Medicare or Medicaid although social security schemes throughout insurance companies are maturing. The majority of insurance companies had denied coverage of birth defects; until recently it seems they are doing so. To cut a long story short, these sophisticated and expensive technologies were not accessible to the vast majority; only a lucky few cases could be treated overseas.

Lack of well-equipped infrastructures in 2004, I encountered the children's hospital of Santiago ("Hospital Infantil Regional Universitario Dr. Arturo Grullón") an unique lifestyle center projected for a tertiary care regional/national with 250 beds, 16 serving as general intermediate care unit (without ventilators nor monitors for invasive pressures, oximeters, etc.), 8 neonatal cradles and incubators, a central laboratory without arterial blood gases machine, a radiology department with a portable x-ray equipment and an old generation CT scan, one echocardiogram machine not sophisticated. Devoid of an individual blood bank and without an extracorporeal circulation machine and other related surplus.

It is important to recall that after my first assessment of the Santiago Children's Hospital on September 2003, I found an appreciable amount of relevant abandoned surplus in one of their storage rooms (unused six servo-ventilators, a dozen of ICU multichannel monitors, two open infant beds and several other equipment which allow me to enable four beds of the recovery room next to the operating room as the first pediatric cardiovascular ICU in that country's Region with all the necessary equipment to launch the cardiovascular surgery program.

It was not until we stablished our CVS program in 2005 that this hospital became a real tertiary facility worth to the Region with our efforts, some donated equipment and the early participation of my surgical team from Venezuela. Unfortunately it did not last long enough, essentially because privation of steady and sustainable finance of the State (Secretary of Health).

In a few instances the Medical Director in charge, repeatedly claimed for not to make more operatives in order to save resources to channel them to other hospital's priorities less expensive because its budgetary constraints. 
Deficiency of highly trained and qualified medical personnel: We bump into only one reliable pediatric cardiologist in town, none cardiovascular pediatric anesthesiologist nor pediatric cardiovascular surgeons (CV) nor scrub nurses ("as curious data this position was deserted in the whole country"), further down not a pediatric perfussionist and not a pediatric cardiac intensivist.

Other priorities in public health issues from local governments: As infectious diseases of childhood: gastroenteritis, diarrheas and dehydration, dengue, chikungunya, malaria, etc. Ordinarily the local Governments are not interested at all in supporting programs that accrued more expensive advanced cardiology and cardiac surgery medical efforts. It is of broad knowledge that the public hospitals have a short and limited budget, therefore have to endorse this type of initiatives is almost prohibitive. "The reduced stock of supplies and medicines for the hospital's routine activities has been a major barrier" and while these "operations" were held, it was reached to the point that was chaotic in the majority of cases. Hence in many instances at the beginning, we had to provide specialized pediatric cardiac surgeries supplies as oxygenators, lines, prosthesis, patches, special sutures and many others.

It is remarkable the initial achievement at the children's hospital of Santiago ("Arturo Grullón") of has operated 111 cases up to intermediate complexities (RACHS 3) with $4 \%$ mortality and fewer than $12 \%$ complications with just a LOCAL trained team during 20042006. This experience was presented at the first meeting of the "World Society of Pediatric and Congenital Heart Surgery" (WSPCHS) held in Washington DC, in May 2007.

\section{Some of our recommendations for such a program were}

1. Develop a pediatric cardiac surgery program is possible, replicable and sustainable

2. The Government and private sector support is essential

3. International assistance is enforced

4. Transform it into a Center of Excellence will enhance to solve the public health problem of the congenital and acquired heart diseases and prevent it

5. In order of perpetuate it in time must be kept out of the politicization

\section{Ours strategies to address the problem}

As a model of sustainability, the programs need a conjoint support between the local government, the visiting teams (funded by NGOs) plus the local hosts. Just as a pyramid where the angles are represented by each of the players. Governments must be aware about the congenital and acquired heart diseases that afflict so many children within their communities creating a public health problem in their countries.

Definitely the Government support is vital, it need a special attention and the investment should be constant and the funds substantially, "not erratic" as when there are regional or presidential elections. The release of further budgets for the hospitals for these special services is essential, altogether with the contributions from the private sector as businesses, clubs, empathy of the NGOs, suppliers of health, churches, etc.

With that scenario, in 2008 a brand new American style private hospital was opened with advanced technology as the best most complete modern hospital in the region and perhaps in the Caribbean, the Hospital Metropolitano de Santiago (HOMS).

We moved to this institution and we launched our mission of developing a "permanent cardiology and cardiovascular surgery program", not only for children but also for adults. I did spread numerous solicitations to almost all my friend's colleagues and fellow members of the now World Society for Pediatric and Congenital Heart Surgery (WSPCHS for its initials in English) without any favorable response, instead I conveyed part of my Venezuelan team for several times, initially sponsored from a local Foundation ("Foundation of Heart to Heart Dominican") that I established with a generous and humanitarian compatriot lady of the society that supported our objectives with certain sustainability for a year, afterward from our own pockets due to the failure of other relevant financial groups in the country to follow this model.

Predictably, this initiative did not last long (only two years) despite having reached the appropriate advanced equipment but limited infrastructure, the greatest disappointment was the lack of native human resourcesin all the terms: doctors, nurses and paramedics for continue and sustain it. On the side that medical schools in general do not meet the standards of world class been worse with nurse's training.

Accreditation/medical license: To get a permanent medical license is quite often a tedious process or the renewal of medical certificates to make our stay in the country at the legal side as to provide permanent or long courses of such ultra-specialized medical services that do not exist in the country. It is required an exam so-called Exequatur and having practiced in a public hospital for two years.

My opinion is that to create and develop a well-established program of pediatric and congenital cardiology and surgery in that country, those requirements of law should be loosened/flexible as there is a precedent done in a public institution in Santo Domingo (CEDIMAT) where they have hired foreign professionals for this purpose.

On the other hand for a short/temporary visit for operational missions, is legally protected by the host team and no major problems, usually the matter is handled by the hospital authorities. However, it is a relevant issue to consider when planning a surgical mission. A concern should be also for those who have medical malpractice insurance and its implication for his/her own abroad coverage outside their country where they work.

\section{Problems found and option solutions}

Staff incentives is a fundamental subject in order to be successful with these efforts, that someone must provide cost-effective incentives for the visiting teams as well as for those native local talents that are involved in such endeavor and that to this point were not taken in consideration and remained inactive. By means of this exposure to foreign groups I am pretty sure they will be refined "doing things" acting altogether under our tutelage ("training in situ"). Besides this, a scholastic incentive is extremely important, in organized CME, supporting assistance to related specialties meetings and formalizing certain networks with foreign centers for intense short internship/ observer ship by way of a more effective method to achieve their training and prepare them to fly "Solo" and solve their own problems by themselves and we are no longer necessary but overseen. In my experience, this way is cost effective and speedy than others used in the past, for each 10 persons that we send out to train, just 1 or 2 returned. This implemented approach will take between 2 to 5 years, always under supervision. The hint also is that the incentives are not only for the staff associations but for the trainers responsible of training locals. 
Every time there is less voluntary altruistic-minded for these "operatives or humanitarian missions" but mostly due to the lacks of incentives discussed above. Moreover, in some circumstances prevails a highly trained volunteers; others come because the low load cases on their centers and thus rise their skills and enlarge their surgical records. Less often a few have attended because their programs are under probation and needed to keep practicing. Keeping in mind that Dominican Republic is a land of lots of tourist attractions, seems more suitable for conspicuous volunteers.

In contrast, at the beginning find local volunteers was not too difficult, but because the lack of incentives again they lost the interest and left the program seeking for better opportunities.

In the Dominican Republic, as in many other countries of Latin America, the medical staff is "underpaid" (\$400-600 doctors and nurses 100 US \$ per month) and find highly trained professionals is a hart mission. It brings to our minds that old saying: "If you pay peanuts you get monkeys".

Cardiology services there are a high demand for qualified pediatric cardiology services. There are quite a few well trained local cardiologists that usually have tools of appropriate basic diagnosis (echo cardiographers mostly analog). The lack of an appropriate pediatric cardiac catheterization room (interventional) and electrophysiology, as well as CT scans or MRI for cardiovascular studies etc., are still essential.

I confront quite often with a large range of errors or incomplete on the echocardiographic diagnosis (up to $60 \%$ at the beginning). The Telemedicine (TeleDiagnosis) was the clue, improving our diagnostic skills for a conducted accurate precision on real or deferred time on those congenital defects: simple, intermediate or complex ones and plan what to do even from a distance. All that was possible through a wonderful experience altogether with a pediatric cardiologist from North Carolina (Dr. James Loher) and his initial software: iCardiogram now Ultralink (www.UltraLink.com).

Ironically despite we have accomplished some early diagnosis (by "fetal echocardiography"), at the moment it is common that those patients are enrolled in a long waiting list and there are no real solutions for them.

Often overlapping efforts in between NGO: evaluating the role of related NGO in the Region, it seem like there was an overlap efforts within them with truthful conflict of interest. These efforts need to be coordinated for better cost-effective results.

\section{Conclusion}

The experiences and lessons learned of "Save A Heart Mission" in the Dominican Republic (DR) were discussed with the conviction that after have tried for more than 10 years against many limitations and obstacles, barely succeeded in the establishment of a permanent Program of Pediatric Cardiology and Cardiovascular Surgeryin the city of Santiago (the 2nd largest city) of the Dominican Republic.

The lack of human factor was the stumbling block and it is a MUST to solve with priority bringing skill personal from abroad to enhance with tutelage in situ the training of the locals as a real legacy of the group/groups to undertake such actions.

However this analysis indicates that similar initiatives in these disciplines may be replicable in emerging countries with such features already discussed so a program of Pediatric Cardiology and Cardiovascular Surgery is possible and sustainable. Nonetheless it is vital that the government and private sector support de strong and steady along with the International assistance.

\section{Acknowledgments}

None.

\section{Conflicts of interest}

The authors declare there is no conflict of interests.

\section{Funding}

None. 